\title{
Biliverdin administration ameliorates cerebral ischemia reperfusion injury in rats and is associated with proinflammatory factor downregulation
}

\author{
JUN-JIE LI ${ }^{*}{ }^{*}$, ZHI-YAO ZOU $^{1 *}$, JIA LIU ${ }^{2}$, LIU-LIN XIONG ${ }^{3}$, HAI-YAN JIANG ${ }^{1}$, \\ TING-HUA WANG ${ }^{2,3}$ and JIAN-LIN SHAO ${ }^{1}$
}

${ }^{1}$ Department of Anesthesiology, The First Affiliated Hospital of Kunming Medical University, Kunming, Yunnan 650032;
${ }^{2}$ Animal Center, Institute of Neuroscience, Kunming Medical University, Kunming, Yunnan 650031;
${ }^{3}$ Department of Anesthesiology and Institute of Neurological Disease, Translational Neuroscience Center,
West China Hospital, Sichuan University, Chengdu, Sichuan 610041, P.R. China

Received May 9, 2016; Accepted March 17, 2017

DOI: $10.3892 / e t m .2017 .4549$

\begin{abstract}
Biliverdin(BV), one of the heme oxygenase-1 (HO-1) catalytic products, has been demonstrated to have protective effects in liver ischemia reperfusion injury (IRI). The present study aimed to explore the effects of BV on cerebral IRI, and to investigate the potential mechanisms thereof. Adult male SD rats, weighing 200-240 g, were randomly divided into sham (group S), cerebral ischemia reperfusion control (group C) and $\mathrm{BV}$ (group BV) groups. Rats in group $\mathrm{C}$ underwent transient middle cerebral artery occlusion (tMCAO) and received $2 \mathrm{ml}$ normal saline; rats in group BV received $\mathrm{BV}(35 \mathrm{mg} / \mathrm{kg})$ intraperitoneally $15 \mathrm{~min}$ prior to reperfusion and $4 \mathrm{~h}$ after reperfusion, then twice a day thereafter for 5 days. Group $\mathrm{S}$ served as the control. Neurological Severity Scores (NSS) were evaluated at days 1-5 following reperfusion. Staining with 2, 3 , 5-triphenyltetrazolium chloride was performed to determine the cerebral infarction at $48 \mathrm{~h}$ post reperfusion. mRNA expression levels of tumor necrosis factor (TNF)- $\alpha$, interleukin (IL)-6, IL-1 $\beta$, inducible nitric oxide synthase (iNOS) and $\mathrm{HO}-1$ in the ischemic cerebral cortex were detected via reverse transcription-quantitative polymerase chain reaction at 3,6 ,
\end{abstract}

Correspondence to: Professor Ting-Hua Wang, Department of Anesthesiology and Institute of Neurological Disease, Translational Neuroscience Center, West China Hospital, Sichuan University, 17 Section 3, South Renmin Road, Chengdu, Sichuan 610041, P.R. China

E-mail: tinghua_neuron@263.net

Professor Jian-Lin Shao, Department of Anesthesiology, The First Affiliated Hospital of Kunming Medical University, 295 Xichang Road, Kunming, Yunnan 650032, P.R. China

E-mail: cmushaojl@aliyun.com

*Contributed equally

Key words: biliverdin, cerebral ischemia, reperfusion injury, anti-inflammation
12 and $24 \mathrm{~h}$ after reperfusion. Western blotting was used to detect the protein expression levels at $3 \mathrm{~h}$ after reperfusion. Compared with group S, the NSS, cerebral infarct volume, and the mRNA and protein expression levels of TNF- $\alpha$, IL-6, IL-1 $\beta$, iNOS and HO-1 of Group C were significantly increased $(\mathrm{P}<0.05)$. However, BV administration significantly improved and reduced these expression levels $(\mathrm{P}<0.01)$. The present study indicates that $\mathrm{BV}$ is able to ameliorate cerebral IRI in rats and that the mechanism may be associated with the downregulation of proinflammatory factors.

\section{Introduction}

Ischemic stroke is a serious disease and threat to the health of millions of people. It is also one of the leading causes of disability and fatality in various industrial countries and still has no effective therapeutic treatments (1). Cerebral ischemia results in the disruption of blood, oxygen and glucose supplies to the brain and a reduction in energy. The generation and accumulation of toxic metabolites, such as glutamate and free radicals may ultimately lead to neurodegeneration (2). The primary method of alleviating neurologic injury caused by brain ischemia is the restoration of the blood flow to the ischemic region rapidly (3). However, blood reperfusion increases the production of excitatory amino acids, oxygen free radicals and intracellular $\mathrm{Ca}^{2+}$, as well as gives rise to damage of the microvascular system, all of which may induce additional damage to the brain tissue, which is termed ischemia reperfusion injury (IRI) $(4,5)$. Injury caused by reperfusion may be more detrimental to health than ischemia itself (6). Previous studies have demonstrated that the inflammatory response is one of the primary factors that leads to IRI $(3,7,8)$.

Inflammation is associated with the pathophysiological process of cerebral IRI. Reperfusion may be promoted by the activities of microglial cells, astrocytes and endothelial cells in the brain, which interact with each other and generate inflammatory mediators, such as cytokines and adhesion molecules, which damage nerve cells $(5,9,10)$. Gene expression levels of interleukin (IL)-1 $\beta$, IL-6 and tumor necrosis factor (TNF)- $\alpha$, 
Table I. Groups and methods performed (time after reperfusion).

\begin{tabular}{lcccc}
\hline & & \multicolumn{2}{c}{ Rats, $\mathrm{n}$} \\
\cline { 2 - 5 } Group & NSS Score (1-5 days) & TTC Stain (48 h) & RT-qPCR (3, 6, 12 and 24 h) & Western blotting (3 h) \\
\hline S & 15 & 5 & 20 & 5 \\
C & 15 & 5 & 20 & 5 \\
BV & 15 & 5 & 20 & 5
\end{tabular}

NSS, Neurological Severity Scores; TTC, 2,3,5-triphenyltetrazolium chloride; RT-qPCR, reverse transcription-quantitative polymerase chain reaction; $\mathrm{S}$, sham; $\mathrm{C}$, vehicle control; $\mathrm{BV}$, biliverdin.

which are regulated by the redox-sensitive transcription factor nuclear factor $(\mathrm{NF})-\kappa \mathrm{B}$, have been demonstrated to rapidly increase the early stage of cerebral IR, to promote an inflammatory response (11-13) and further aggravate cerebral IR. Accordingly, reducing the inflammatory response may have a positive effect on the prognosis of ischemic diseases.

Heme oxygenase (HO)-1, an inducible type of heme oxygenase, is a rate-limiting enzyme of heme metabolism, which catalyzes heme to $\mathrm{Fe}^{2+}$, carbon monoxide and biliverdin (BV) (14). BV is rapidly converted to bilirubin by $\mathrm{BV}$ reductase (15). A number of studies have demonstrated that HO-1 has neuroprotective effects including antioxidant, anti-inflammatory, and anti-apoptotic effects following cerebral IRI (16-18). In addition, BV, which is a catalytic product of HO-1, has been demonstrated to exhibit potent anti-inflammatory effects in various studies, in both in vivo and in vitro models (19-21). Previous studies have shown that exogenous $\mathrm{BV}$ is able to downregulate the expression of adhesion molecules and inhibit the aggregation of white blood cells, thereby reducing the generation of cytokines and chemotaxis factors and the expression of pro-inflammatory proteins, such as cyclooxygenase- 2 and cytochrome P450, ultimately ameliorating inflammation (22). Furthermore, BV has been shown to restrain the complement cascade reaction (23) and decrease the expression of cytokines, such as TNF- $\alpha$ and IL-6, by reducing the reaction activity of $\mathrm{NF}-\kappa \mathrm{B}$ in a lipopolysaccharide (LPS)-induced injury model (24). However, the effect of BV in cerebral IRI is still unknown, and the application of $\mathrm{BV}$ to treat brain IRI is limited.

The present study aimed to investigate the effects of exogenous BV on cerebral IRI and explored the potential neuroprotective mechanism.

\section{Materials and methods}

Animals and grouping. A total of 135 male Sprague-Dawley rats, age 6-8 weeks, weighing 200-240 g, were provided by the Laboratory Zoology Department at Kunming Medical University (Kunming, China). All rats were maintained in plastic cages with soft bedding in a temperature-controlled room at $21-25^{\circ} \mathrm{C}$, with a humidity of $45-50 \%$ and a $12 \mathrm{~h}$ light/dark cycle. Rats had ad libitum access to food and water. Study protocols followed the guidelines for Laboratory Animal Care and Safety as issued by the Unites States National Institutes of Health. Animal care and all experimental protocols were approved by and performed according to the Guidelines of the Animal Care \& Welfare Committee of Kunming Medical University. Rats were randomly divided into the sham (group S; sham operation, $\mathrm{n}=45$ ); vehicle control (group C; IRI + normal saline, $n=45$ ); and BV (group BV; IRI + BV treatment, $n=45$ ) groups, which are indicated in Table I.

Animal transient middle cerebral artery occlusion model $(t M C A O)$. According to the Zea-Longa method (25), rats with tMCAO model of cerebral IRI were established. Briefly, rats were anesthetized with $3.6 \%$ chloral hydrate $(350 \mathrm{mg} / \mathrm{kg}$; Tianjin Guangfu Fine Chemical Research Institute, Tianjin, China) intraperitoneally and the right common carotid artery was exposed and carefully separated. The middle cerebral artery (MCA) was obturated by inserting a nylon thread coated with polylysine (diameter, $0.24 \mathrm{~mm}$ ) into the internal carotid artery, which was advanced further until it approached the starting point of the MCA. The inserting length was $18 \pm 2 \mathrm{~mm}$. Group $S$ rats underwent the same procedures without inserting the nylon thread. After $2 \mathrm{~h}$ of tMCAO, cerebral blood flow was recovered by removing the nylon thread. When they recovered from anesthesia, rats were scored according to the Zea-Longa scoring system, as reported previously (26). The scoring was as follows: 0 points, no symptoms of neurologic impairment; 1 point, side front paw could not stretch completely; 2 points, paw rotated inwards when walking; 3 points, paw tilted inwards when walking; and 4 points, failed to spontaneously walk or loss of consciousness. According to the experimental requirements, rats that scored 0 or 4 points were excluded from the present study; scores of 1, 2 and 3 points indicated the model was successful.

$B V$ treatment. BV hydrochloride (Frontier Scientific, Inc., Logan, UT, USA) was dissolved in 0.2 $\mathrm{M} \mathrm{NaOH}$ solution and adjusted to $\mathrm{pH} 7.4$ with $\mathrm{HCl}$. After diluting with saline, BV (35 $\mathrm{mg} / \mathrm{kg}$ in $2 \mathrm{ml}$ ) was intraperitoneally administered to rats $15 \mathrm{~min}$ prior to reperfusion, once again $4 \mathrm{~h}$ after reperfusion and twice a day thereafter for 5 days. In group $\mathrm{C}$, the same volume of saline was administered using the same method.

Neural behavioral test. Rats in groups C and BV were scored using the previously reported Neurological Severity Scores (NSS) scoring system (27) at days 1-5 after reperfusion, respectively. Group $\mathrm{S}$ were also scored at the same time points. The NSS included four aspects: Study of feeling (sensory tests 
Table II. Sequences of primers and probes.

\begin{tabular}{lll}
\hline Gene & Primer direction/probe & Sequence $\left(5^{\prime}-3^{\prime}\right)$ \\
\hline TNF- $\alpha$ & Forward & GCCCACGTCGTAGCAA \\
& Reverse & GTCTTTGAGATCCATGCCAT \\
IL-6 & Probe & CTCACGCCACTCCAGCTGCTC \\
& Forward & AGAAGACCAGAGCAGATTTT \\
& Reverse & GAGAAAGAGTTGTGCAATG \\
IL-1 $\beta$ & Probe & CCAGTTTGGAAGCATCCATC \\
& Forward & GAGCTGAAAGCTCTCCACCT \\
iNOS & Reverse & TTCCATCTTCTTCTTTGGGT \\
& Probe & CCTGTGGCCTTGGGCCTC \\
& Forward & ATCGCTGGCTACCAGATGC \\
HO-1 & Reverse & ATGGTCACCTCCAGCACAAG \\
& Probe & GCCACCTTGGAGTTCACCCAGTTG \\
$\beta$-actin & Forward & CCCCACCAAGTTCAAACAGC \\
& Reverse & CAATGTTGAGCAGGAAGGCG \\
& Probe & CGCATGAACACTCTGGAGATGACCC \\
& Forward & GAAGATCAAGATCATTGCTCCT
\end{tabular}

TNF, tumor necrosis factor; IL, interleukin; iNOS, inducible nitric oxide synthase; HO, heme oxygenase.

including visual, tactile and proprioceptive test; 2 points were awarded), movement (motor tests including raising rat by the tail and placing rat on the floor; 6 points were awarded), reflection (reflexes absent and abnormal movements; 4 points were awarded) and balance (beam balance tests; 6 points were awarded). Scoring was defined as follows: 1-6, mild injury; 7-12, moderate injury; and 13-18, severe injury.

Mensuration of cerebral infarct volume by 2,3,5-triphenyltetrazolium chloride (TTC) staining. To evaluate the infarct volume of the ischemic cerebral hemisphere, brains $(n=5$ for each group) were removed 2 days after reperfusion and cut into five coronal sections of $2-\mathrm{mm}$ thickness. Sections were incubated in 2\% TTC solution (Sigma-Aldrich; Merk KGaA, Darmstadt, Germany) at $37^{\circ} \mathrm{C}$ for $20 \mathrm{~min}$. After staining, the sections were washed in phosphate-buffered saline three times for $1 \mathrm{~min}$ each and fixed in $4 \%$ paraformaldehyde at room temperature for $24 \mathrm{~h}$. Color images of these sections were directly obtained with a stereomicroscope and (magnification, $\mathrm{x} 5$ ) then the infarct areas of each section was measured using Image $\mathrm{J}$ software version 1.43 (National Institutes of Health, Bethesda, MA, USA). In order to exclude the interference of cerebral edema after cerebral IRI, the infarct volume percentage in the ischemic cerebral hemisphere was calculated using the following equation: (contralateral hemisphere volume-volume of non-ischemic ipsilateral hemisphere)/the contralateral hemisphere, as previously reported (28).

Reverse transcription-quantitative polymerase chain reaction (RT-qPCR). RT-qPCR was used to detect the relative mRNA expression levels of TNF- $\alpha$, IL-6, IL-1 $\beta$, iNOS and HO-1 at 3, 6,12 and $24 \mathrm{~h}$ following reperfusion. Each group contained five samples and was repeated three times. $\beta$-actin was used as internal control. The brain cortex of ischemia region was homogenized in TRIzol reagent (Life Technologies; Thermo Fisher Scientific, Inc., Waltham, MA, USA) and total RNA was extracted from the sample according to the manufacturer's protocol. The concentration of the total RNA was determined with spectrophotometric optical density measurement. Reverse transcription reactions were then performed using the RevertAid First Strand cDNA Synthesis kit (cat. no. K1622; Thermo Fisher Scientific, Inc.). Each reaction tube contained $3 \mu \mathrm{g}$ total RNA in a reaction mixture containing $1 \mu \mathrm{l}$ OLigDT, $4 \mu \mathrm{l}$ XX reaction buffer, $1 \mu \mathrm{l}$ ribonuclease inhibitor, $2 \mu 110 \mathrm{mM}$ dNTP mix, $1 \mu$ l RevertAid M-MuLV Reverse Transcriptase and diethylpyrocarbonate-treated water to a final volume of $20 \mu \mathrm{l}$. Reverse transcription reactions were performed using a DNA thermal cycler (T100; Bio-Rad Laboratories, Inc., Hercules, CA, USA) at $42^{\circ} \mathrm{C}$ for $60 \mathrm{~min}$ and $75^{\circ} \mathrm{C}$ for $5 \mathrm{~min}$. PCR was performed in a DNA thermal cycler (CFX96; Bio-Rad Laboratories, Inc.) according to the following standard protocol: One cycle of $94^{\circ} \mathrm{C}$ for $5 \mathrm{~min} ; 40$ cycles of $94^{\circ} \mathrm{C}$ for $10 \mathrm{sec}$, annealing for $10 \mathrm{sec}$ (TNF- $\alpha$, IL- 6 and $\beta$-actin:, $52^{\circ} \mathrm{C}$; IL-1 $\beta$; $51^{\circ} \mathrm{C}$; iNOS, $55^{\circ} \mathrm{C}$; HO- $1,53^{\circ} \mathrm{C}$ ) and $60^{\circ} \mathrm{C}$ for $20 \mathrm{sec}$. Each reaction tube contained $0.6 \mu \mathrm{l}$ forward primer, $0.6 \mu 1$ reverse primer, 0.6 $\mu 1$ TaqMan probe (Sangon Biotech Co., Ltd., Shanghai, China), $1 \mu \mathrm{l}$ cDNA, $10 \mu$ l PCR Master Mix (Life Technologies; Thermo Fisher Scientific, Inc.) and $7.2 \mu \mathrm{l}$ water. The primer and probe sequences used are listed in Table II. The relative mRNA expression levels were calculated with standardization to $\beta$-actin by using the $2^{-\Delta \Delta \mathrm{Cq}}$ method (29).

Western blotting. Western blotting was used to detect the relative protein expression levels of TNF- $\alpha$, IL-6, IL-1 $\beta$, iNOS and 
HO-1. Cortex samples of the ischemic region were harvested $3 \mathrm{~h}$ after reperfusion and homogenized in ice-cold radioimmunoprecipitation assay lysis buffer (Biosharp, Hefei, China) for $30 \mathrm{~min}$. One cocktail pill (Roche Diagnostics $\mathrm{GmbH}$, Mannheim, Germany), which consisted of protease inhibitors, was added to $50 \mathrm{ml}$ buffer. After cell lysis, samples were centrifuged at $20,392 \times \mathrm{g}$ at $4^{\circ} \mathrm{C}$ for $15 \mathrm{~min}$ and the supernatant was collected. The protein concentration of the supernatant was measured using a bicinchoninic acid protein assay reagent kit (Beyotime Institute of Biotechnology, Haimen, China). Subsequently, protein was mixed with sample buffer and boiled for $5 \mathrm{~min}$. A total of $80 \mu \mathrm{g}$ protein was loaded per lane and separated using $10-15 \%$ SDS-PAGE at $90 \mathrm{~V}$ for $40 \mathrm{~min}$ and then $140 \mathrm{~V}$ for $1 \mathrm{~h}$. The separated proteins were transferred from the gel to cellulose nitrate membranes (GE Healthcare Life Sciences, Chalfont, UK) and blocked in 5\% non-fat milk dissolved in $1 \mathrm{X}$ TBS at $37^{\circ} \mathrm{C}$ for $1 \mathrm{~h}$. Subsequently, membranes were incubated with primary antibody overnight at $4^{\circ} \mathrm{C}$. The following primary antibodies were used: Rabbit anti-TNF- $\alpha$ (1:200; ab6671; Abcam, Cambridge, UK); rabbit anti-IL-6 (1:1,000; ab9324; Abcam); rabbit anti-IL-1 1 (1:500; ab9722; Abcam); rabbit anti-iNOS (1:1,000; AB5382; EMD Millipore, Inc., Billerica, MA, USA); rabbit anti-HO-1 (1:1,000; AB1284; EMD Millipore, Inc.); and mouse anti- $\beta$-actin $(1: 1,000$; ab3280; Abcam). Membranes were washed with 1X TBST three times (10 min each). Horseradish peroxidase-conjugated goat anti-rabbit secondary antibody and goat anti-mouse for $\beta$-actin (1:5,000; Zhongshan Golden Bridge Biotechnology Co., Ltd. China) were incubated in $1 \mathrm{X}$ TBST for $1 \mathrm{~h}$ at room temperature. Membranes were rinsed in TBST three times and were visualized using enhanced chemiluminescence detection reagents (Beyotime Institute of Biotechnology). The mean gray value was measured using Image $\mathrm{J} 1.43$ software and the relative protein expression was calculated against the ratio of $\beta$-actin.

Statistical analysis. Statistical analysis was performed using SPSS 19.0 software (IBM SPSS, Armonk, NY, USA). Values were expressed as mean \pm standard deviation. For multiple group comparison, analysis of variance with Tukey's post hoc test was applied and differences of $\mathrm{P}<0.05$ were considered to indicate a statistically significant difference.

\section{Results}

Effect of $B V$ on the neurologic deficit after reperfusion in rats. Neurological deficit was examined and scored with NSS at days 1-5 after reperfusion. The scores were $1.20 \pm 0.24$, $0.93 \pm 0.30,0.60 \pm 0.56,0.33 \pm 0.20$ and 0 in group $\mathrm{S}$ from day 1 to 5 , respectively. Group $\mathrm{C}$ rats exhibited scores of $5.47 \pm 1.57$, $5.07 \pm 0.74,4.20 \pm 0.82,4.20 \pm 0.83$ and $3.23 \pm 0.82$ from day 1 to 5 , respectively. Fig. 1 indicates that group C exhibited significantly increased NSS compared with group $\mathrm{S}$ at all time points $(\mathrm{P}<0.05)$. Compared with group $\mathrm{C}, \mathrm{BV}$ treatment markedly reduced the NSS of rats in group BV $(5.17 \pm 0.67,4.87 \pm 0.40$, $3.93 \pm 0.38,3.50 \pm 0.69$ and $3.10 \pm 0.55$ from day 1 to 5 , respectively; Fig. 1).

Reduction of cerebral infarction volume in rats treated with $B V$. TTC staining was used to detect the infarct volume $48 \mathrm{~h}$ after

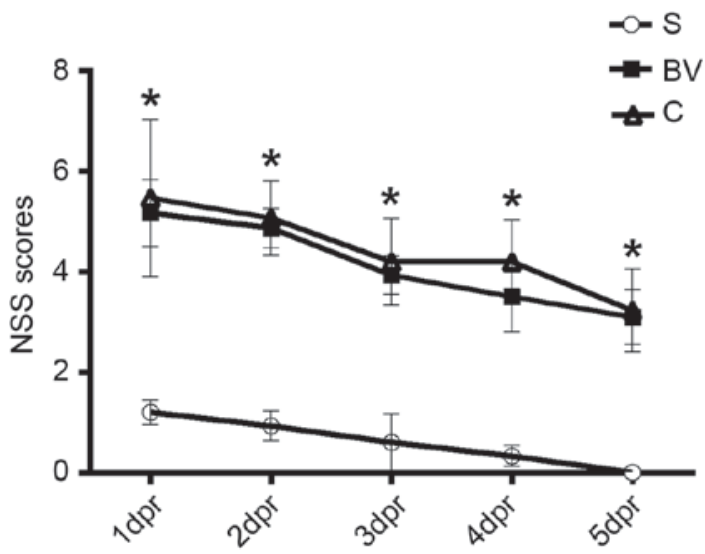

Figure 1. NSS in group S, C and BV rats. Compared with group S, the scores were significantly higher at days $1-5$ in group $\mathrm{C}$, and BV administration markedly reduced the scores compared with group C. Data were presented as mean \pm standard deviation $\left(\mathrm{n}=15\right.$ in each group). ${ }^{*} \mathrm{P}<0.05$ vs. group $\mathrm{S}$. NSS, Neurological Severity Scores; BV, biliverdin; S, sham; C, vehicle control; dpr, days post reperfusion.

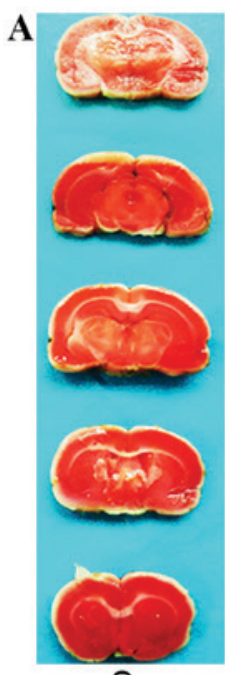

S

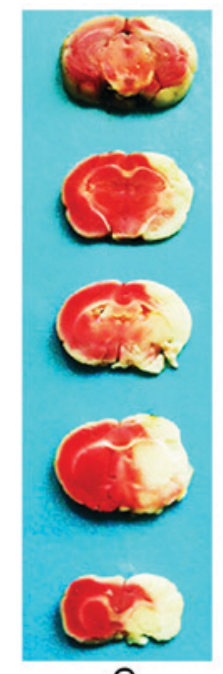

C

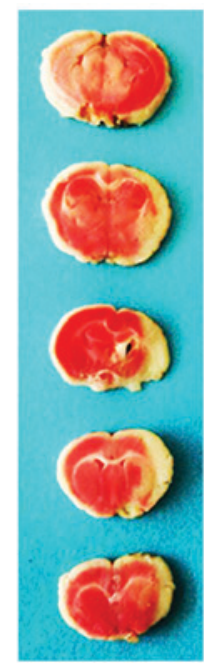

BV
B

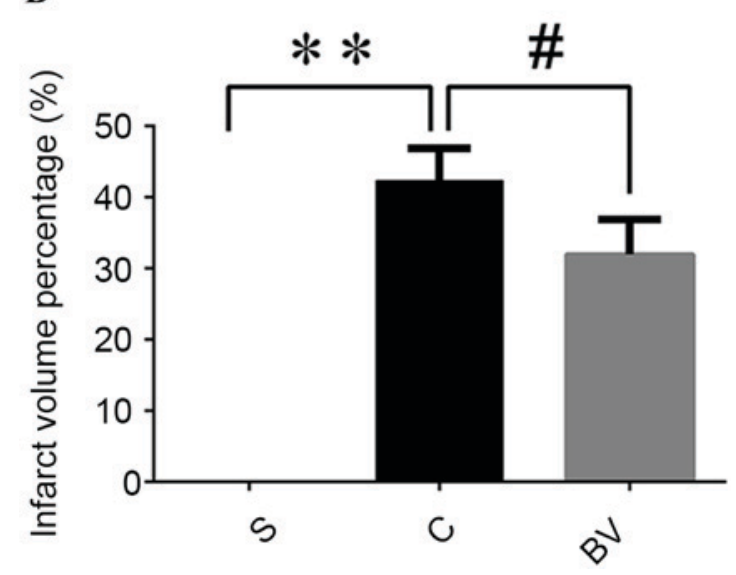

Figure 2. Alternations of brain infarction following BV administration. (A) 2,3,5-triphenyltetrazolium chloride-stained coronal slices at $48 \mathrm{~h}$ after reperfusion from group S, C and BV. (B) Representative bar graph for the infarct volume percentage of cerebral hemisphere. The volume in group $\mathrm{C}$ was significantly greater than that in group $\mathrm{S}$. A significant reduction of infarct volume was detected at the cerebral hemisphere in group BV. Data were presented as mean \pm standard deviation $(\mathrm{n}=5) .{ }^{* *} \mathrm{P}<0.01 ;{ }^{*} \mathrm{P}<0.05 \mathrm{BV}$, biliverdin; S, sham; C, vehicle control. 
A

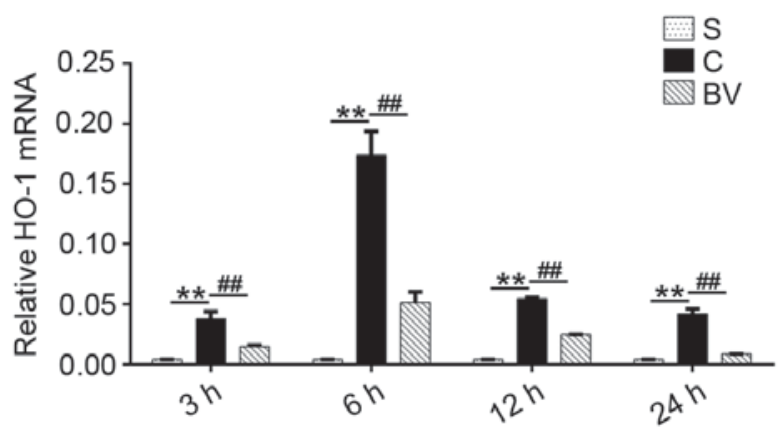

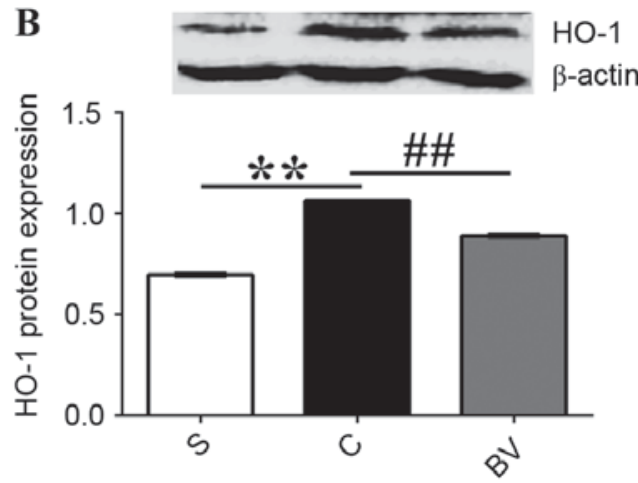

Figure 3. Effect of BV administration on the expression levels of HO-1 mRNA and protein in the ischemia cortex. (A) Relative expression levels of HO-1 mRNA at 3, 6, 12 and $24 \mathrm{~h}$ after reperfusion. (B) Relative expression levels of HO-1 protein 3 h after reperfusion. Data were presented as mean \pm standard deviation ( $\mathrm{n}=5$ in each group). ${ }^{* *} \mathrm{P}<0.01 ;{ }^{\# \#} \mathrm{P}<0.01$. BV, biliverdin; HO-1, heme oxygenase-1; $\mathrm{S}$, sham; $\mathrm{C}$, vehicle control.
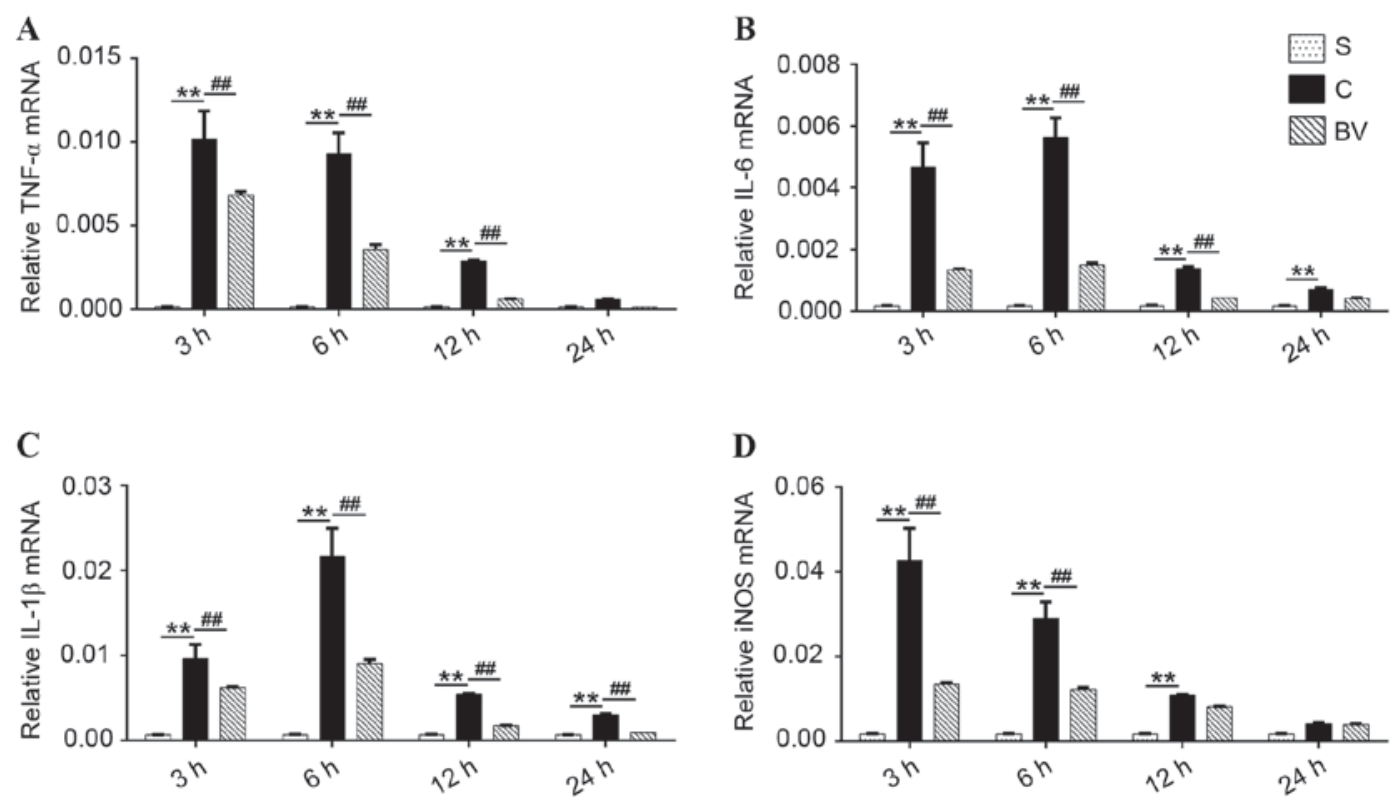

Figure 4. Effect of BV administration on the mRNA expression levels of TNF- $\alpha$, IL-6, IL-1 $\beta$ and iNOS in the ischemia cortex. (A-D) mRNA expressional changes in TNF- $\alpha$, IL-6, IL-1 $\beta$ and iNOS, respectively at $3,6,12$ and $24 \mathrm{~h}$ after reperfusion. Brain ischemia reperfusion injury significantly increased the mRNA expression levels of TNF- $\alpha, \mathrm{IL}-6, \mathrm{IL}-1 \beta$, and iNOS. BV administration reversed these changes. Data were presented as mean \pm standard deviation ( $\mathrm{n}=5$ in each group). ${ }^{* *} \mathrm{P}<0.01 ;{ }^{\# \#} \mathrm{P}<0.01$. BV, biliverdin; TNF, tumor necrosis factor; IL, interleukin; iNOS, inducible nitric oxide synthase; $\mathrm{S}$, sham; $\mathrm{C}$, control; BV, biliverdin.

reperfusion. As observed directly, no infarction was detected in group $\mathrm{S}$, whereas extensive infarction was developed in the lateral cortex in group $\mathrm{C}$ compared with group S; BV treatment markedly reduced the infarction compared with group $\mathrm{C}$ (Fig. 2A). Through quantitative analysis, in group C, the infarct volume percentage of the ischemic cerebral hemisphere was significantly higher than that of Group S $(42.28 \pm 4.59$ vs. $0.00 \pm 0.00$, respectively; $\mathrm{P}<0.01$; Fig. $2 \mathrm{~B}$ ). However, BV treatment significantly reduced the infarct volume from $42.28 \pm 4.59$ to $31.95 \pm 4.88$ compared with group $\mathrm{C}(\mathrm{P}<0.05$; Fig $2 \mathrm{~B})$.

$B V$ treatment inhibited the $m R N A$ and protein expression levels of $\mathrm{HO}$-1. Compared with group $\mathrm{S}$, the mRNA expression levels of HO-1 were significantly upregulated at 3, 6, 12 and $24 \mathrm{~h}$ following ischemia reperfusion $(\mathrm{P}<0.01$; Fig. $3 \mathrm{~A})$. However, BV treatment significantly downregulated the mRNA expression levels of $\mathrm{HO}-1$ at these time points compared with group $\mathrm{C}$
$(\mathrm{P}<0.01$; Fig 3A). Additionally, the protein expression levels of HO-1 were significantly increased $3 \mathrm{~h}$ following reperfusion compared with group $\mathrm{S}(\mathrm{P}<0.01)$; however, these expression levels were significantly decreased by $\mathrm{BV}$ treatment compared with group $\mathrm{C}(\mathrm{P}<0.01$; Fig 3B).

mRNA expression levels of TNF- $\alpha, I L-6, I L-1 \beta$ and iNOS were downregulated by $B V$ after cerebral IRI. The results of RT-qPCR showed that low expression levels of TNF- $\alpha$, IL-6, IL-1 $\beta$ and iNOS mRNA were detected in group S. However, in group C, the mRNA expression levels of TNF- $\alpha$, IL-6, IL-1 $\beta$ and iNOS were significantly increased compared with group $\mathrm{S}(\mathrm{P}<0.01)$. Furthermore, TNF- $\alpha$ and iNOS mRNA expression levels in group $\mathrm{C}$ peaked at $3 \mathrm{~h}$ then gradually reduced to lower levels. However, IL- 6 and IL-1 $\beta$ mRNA expression levels peaked at $6 \mathrm{~h}$ and gradually decreased to lower levels (Fig. 4A-D). BV treatment significantly decreased 

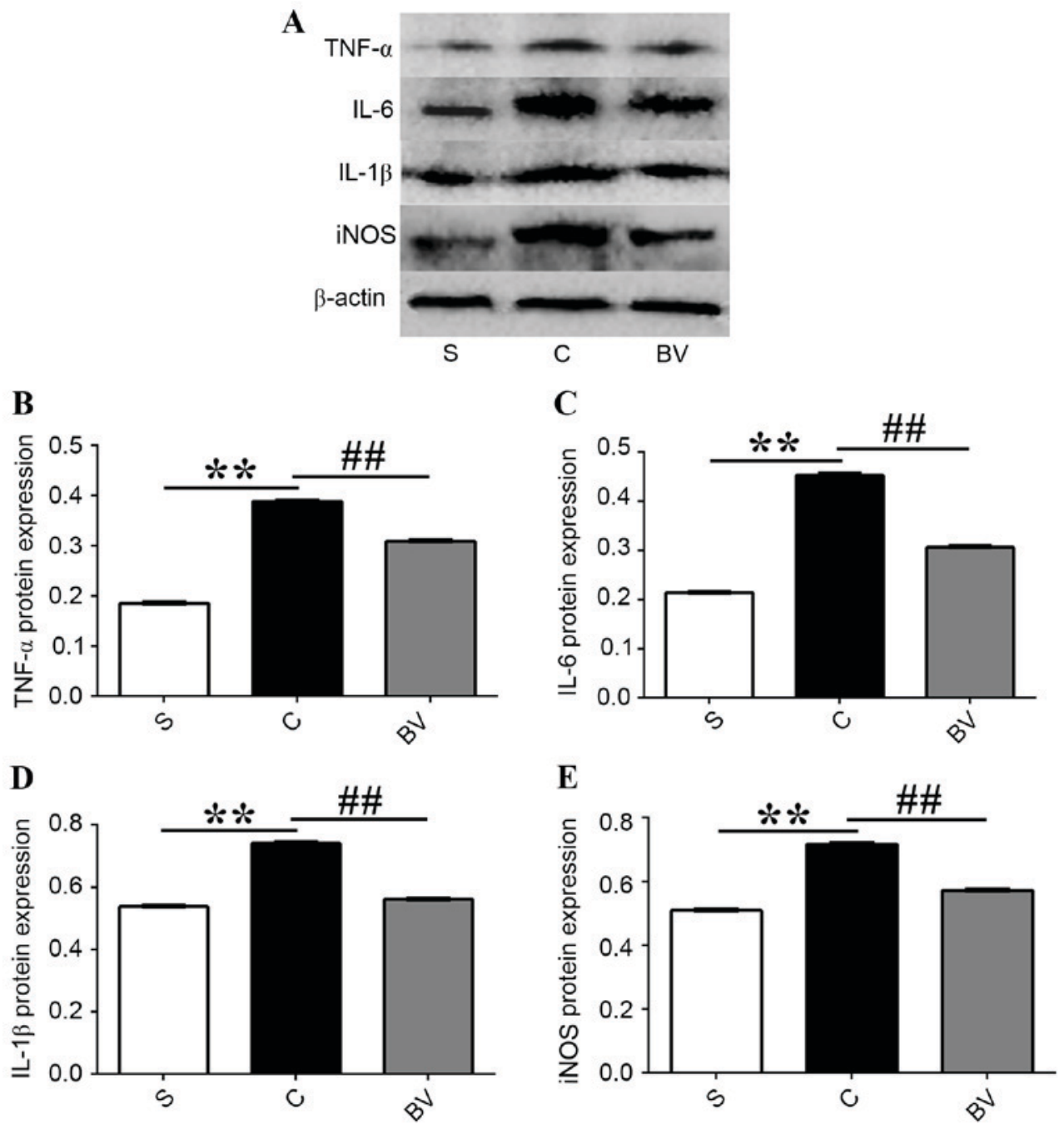

Figure 5. Effect of BV administration on the protein expression levels of TNF- $\alpha$, IL-6, IL-1 $\beta$ and iNOS in the ischemia cortex $3 \mathrm{~h}$ after reperfusion. (A) Western blotting of TNF- $\alpha$, IL-6, IL-1 $\beta$ and iNOS $3 \mathrm{~h}$ after reperfusion; (B) Relative protein expression levels of TNF- $\alpha$, (C) IL-6, (D) IL-1 $\beta$ and (E) iNOS. Data were presented as mean \pm standard deviation $\left(\mathrm{n}=5\right.$ in each group) ${ }^{* *} \mathrm{P}<0.01 ;{ }^{\# /} \mathrm{P}<0.01$. BV, biliverdin; TNF, tumor necrosis factor; IL, interleukin; iNOS, inducible nitric oxide synthase; $\mathrm{S}$, sham; $\mathrm{C}$, vehicle control.

TNF- $\alpha$ and IL-6 mRNA expression at 3, 6, and $12 \mathrm{~h}$ following reperfusion $(\mathrm{P}<0.01)$; however, no significant difference was indicated at $24 \mathrm{~h}$ compared with group C (Fig. 4A and B); IL-1 $\beta$ mRNA expression levels were significantly decreased after BV treatment at 3, 6, 12 and $24 \mathrm{~h}$ compared with group $\mathrm{C}(\mathrm{P}<0.01$; Fig. 4C). Furthermore, compared with group $\mathrm{C}$, the expression levels of iNOS mRNA were significantly reduced following $\mathrm{BV}$ treatment at 3 and $6 \mathrm{~h}(\mathrm{P}<0.01)$; however, no significant difference at 12 and $24 \mathrm{~h}$ was indicated $(\mathrm{P}>0.05$; Fig. 4D).

$B V$ administration downregulated the protein expression levels of TNF- $\alpha, I L-6, I L-1 \beta$ and iNOS after cerebral IRI. Western blotting was used to investigate the effects of BV on the protein expression levels of TNF- $\alpha$, IL-6, IL-1 $\beta$ and iNOS after cerebral IRI (Fig. 5A). Western blotting analysis revealed that the protein expression levels of TNF- $\alpha$, IL-6, IL-1 $\beta$ and iNOS were significantly increased at $3 \mathrm{~h}$ following IRI compared with group $\mathrm{S}(\mathrm{P}<0.01)$; whereas, compared with group $\mathrm{C}, \mathrm{BV}$ treatment significantly decreased the expression levels of these proteins $(\mathrm{P}<0.01$; Fig. 5B-E).

\section{Discussion}

The present study investigated whether intraperitoneal administration of $35 \mathrm{mg} / \mathrm{kg}$ BV was able to ameliorate brain IRI. Furthermore, the feasible mechanism involved in the downregulation of proinflammatory factors TNF- $\alpha$, IL-6, IL-1 $\beta$, and iNOS was explored.

In the present study, tMCAO was employed to establish a rat model of cerebral IRI. The NSS, which is a standard for evaluation of neurological deficit in rats (27), was significantly higher in group $\mathrm{C}$ than that of group $\mathrm{S}$ at days 1-5 after reperfusion. In addition, TTC staining indicated significant brain infarction following IRI. It is understood that the brain weight accounts for only $2 \%$ of body weight; however, the oxygen consumption of the brain accounts for $20 \%$ of the total body oxygen consumption (30). The brain is intensely sensitive to ischemia and hypoxia; therefore, ischemia following a prolonged period of time may lead to brain infarction (31). Previous animal studies have demonstrated that brain tissue may incur more extensive infarction when blood flow is restored after a period of ischemia than permanent cerebral 


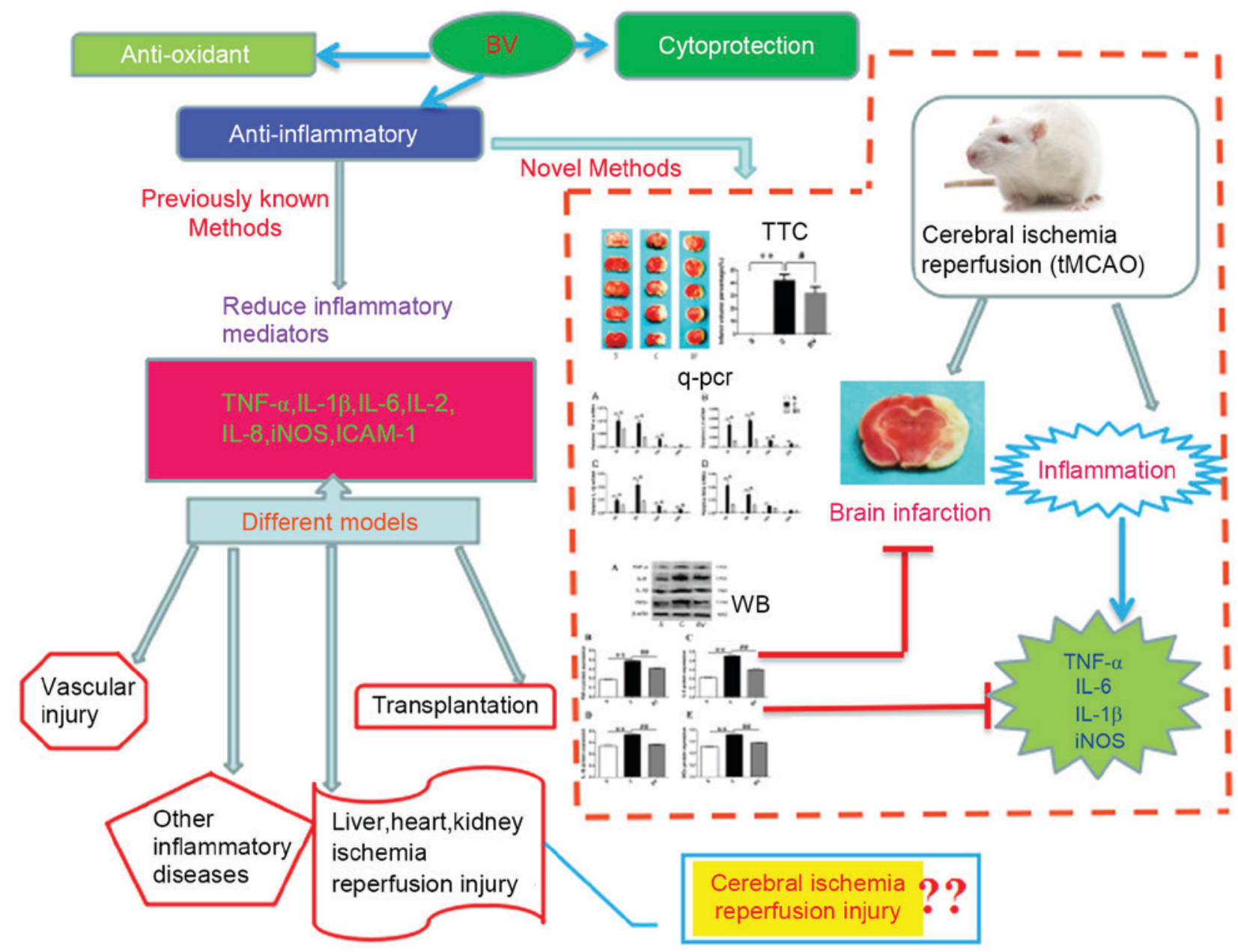

Figure 6. Summaries for the protective role and related mechanisms of BV on the disease models. As previously reported, BV administration may have a protective role in diverse disease models, such as vascular injury, organ transplantation, ischemia reperfusion injury of liver, heart and kidney and other inflammatory diseases. The underlying mechanisms were associated with cytoprotection, anti-inflammation and antioxidant production. In addition, the present study concluded that BV has a protective role in the cerebral ischemia reperfusion injury by promoting downregulation of TNF- $\alpha$, IL-6, IL-1 $\beta$ and iNOS, indicating BV may be applied in the treatment of cerebral ischemia reperfusion injury and reduce inflammation. BV, biliverdin; TNF, tumor necrosis factor; IL, interleukin; iNOS, inducible nitric oxide synthase; ICAM-1, intercellular adhesion molecule 1; tMCAO, transient middle cerebral artery occlusion; WB, western blotting; qPCR, quantitative polymerase chain reaction; TTC, 2,3,5-triphenyltetrazolium chloride.

ischemia $(32,33)$. The present study indicated that ischemic cerebral hemisphere infarction volume increased significantly $48 \mathrm{~h}$ after reperfusion, which revealed that cerebral infarction occurred in the injured rats. Together, this demonstrates that the present models of tMCAO were successful and that cerebral ischemia reperfusion damaged the nervous function.

Results from the present study detected increased mRNA and protein expression levels of TNF- $\alpha$, IL-6, IL-1 $\beta$ and iNOS were accompanied with the neurological deficit. Previous reports have suggested that the inflammatory response has a vital role in the process of cerebral ischemia reperfusion and aggravates IRI $(5,11,34)$. Therefore, anti-inflammatory treatment may alleviate cerebral IRI and is also expected to improve the prognosis of ischemic stroke.

In the present study, $35 \mathrm{mg} / \mathrm{kg}$ BV was administered intraperitoneally $15 \mathrm{~min}$ prior to reperfusion, once again $4 \mathrm{~h}$ after reperfusion and twice a day thereafter. BV was able to ameliorate neurological behavior and significantly reduced brain infarction after brain ischemia/reperfusion. There are two reasons behind choosing the $35 \mathrm{mg} / \mathrm{kg}$ dose of BV: i) The generated bilirubin after this dose would be raised but not beyond the highest acceptable normal range of $<1 \mathrm{mg} / \mathrm{dl}$ (19); and ii) BV has been shown to exert anti-inflammatory effects at this dose in a liver graft IRI model (35).

HO-1 is a protective enzyme, which has a protective effect on cerebral ischemia and traumatic brain injury $(33,36,37)$. Cerebral ischemia stress may significantly increase the generation of HO-1, resulting in the effect of anti-ischemic injury $(38,39)$. BV, as one of the metabolites of HO-1 catalytic oxidation, has been shown to influence the change in HO-1 expression in a study on an inflammatory injury model of the cornea, which demonstrated that BV treatment downregulated the expression of HO-1 mRNA (22). In addition, BV has also been indicated to inhibit the expression levels of both HO-1 mRNA and protein in a study of IRI of liver (40) transplantation as well as in the lungs of rats (41), The present results showed that HO-1 mRNA and protein expression levels were significantly upregulated after ischemia reperfusion; however, treatment with BV significantly downregulated the expression levels of HO-1 protein and mRNA, which suggests that BV is able to successfully initiate a reaction in the body, and reveals that $\mathrm{BV}$ is able to regulate the expression of HO-1 by negative 
feedback. Previous studies have demonstrated that BV has potent protective roles in diverse disease models (35,41-43), such as a syngeneic small bowel $(40,44)$, liver transplantation (40), cardiac and renal transplantation (45), liver reperfusion injury (46) and lung reperfusion injury (19) models. These studies were indicative of the therapeutic potential of BV in treating clinical diseases. However, whether BV administration may protect the brain and improve the neurological function after cerebral IRI is still unknown, and few reports have focused on this. This mechanism also requires further investigating.

In the present study, RT-qPCR and western blotting indicated that the expression levels of TNF- $\alpha$, IL-6, IL-1 $\beta$ and iNOS mRNA and protein were significantly upregulated after cerebral IRI. However, BV treatment significantly downregulated the expression levels of these factors. This finding indicated that the inflammatory mediators TNF- $\alpha$, IL- 6 , IL-1 $\beta$ and iNOS were largely generated in brain tissue and promoted the inflammatory response after cerebral IRI; however, BV effectively reduced the expression of these factors and inhibited the inflammatory response, thus, ultimately contributing to the improvement of neurological function after cerebral IRI.

In the early stage of cerebral ischemia/reperfusion, proinflammatory cytokines TNF- $\alpha$ and IL-1 $1 \beta$ are key factors that promote the inflammatory response and initiate the process of inflammatory reaction, promote the expression of cell adhesion molecules and the infiltration of peripheral leukocytes, thus aggravating brain tissue damage caused by ischemia reperfusion $(34,47-49)$. As reported previously (13), TNF- $\alpha$, IL-6 and IL-1 $\beta$ mRNA were significantly upregulated in the ischemic cortex from 3-72 $\mathrm{h}$ and peaked at $6 \mathrm{~h}$ after ischemia. Therefore, TNF- $\alpha$, IL- 6 and IL- $1 \beta$ are considered three of the most important cytokines implicated in cerebral IRI $(13,50)$. iNOS is an important proinflammatory mediator during the inflammatory response and expression of iNOS has been indicated to be significantly increased by ischemia reperfusion of the intestine (44), heart and kidneys (45). Similarly, the present findings revealed that the expression levels of iNOS were significantly upregulated after focal cerebral ischemia reperfusion and that $\mathrm{BV}$ administration significantly decreased iNOS expression. BV, one of the three products of heme catabolism, has been demonstrated to have a protective role in various models of inflammation, liver and lung IRI and organ transplantation $(43,44,46)$, and it has been reported to have cytoprotective, anti-inflammatory, and anti-oxidant effects (42). However, the possible molecular mechanism of the protective role of BV in cerebral IRI remains unknown. On probing the mechanism underlying the protective effects of BV administration on brain tissue after IRI, we discovered that BV administration repressed cerebral IRI-induced gene and protein expression of the inflammatory mediators TNF- $\alpha$, IL- 6 , IL-1 $\beta$ and iNOS. To the best of our knowledge, the present study is the first to suggest that the protective effects of BV administration on cerebral IRI may occur by targeting some elements within the anti-inflammatory pathway. The present study has provided novel insights into the anti-inflammatory effects of BV on a defined model of cerebral IRI (tMCAO) (Fig. 6).

In conclusion, the present study indicated that cerebral IRI induced inflammation, as indicated by the increase in gene and protein expression levels of inflammatory mediators TNF- $\alpha$, IL-6, IL-1 $\beta$ and iNOS. BV treatment appeared to promote the downregulation of these inflammatory mediators and reduced the extent of cerebral infarction. Together, these findings suggested that BV suppressed IRI-induced brain injury, at least in part, through anti-inflammatory mechanisms.

\section{Acknowledgements}

The present study was supported by a grant from The Cultivation of Youth Leaders in Academic and Technical Talents Foundation of Yunnan Province, China (CN) (grant no. 2012HB030). The authors also would like to thank the Medical University of Kunming (Kunming, China) for its technical support.

\section{References}

1. Zhang M, Wang S, Mao L, Leak RK, Shi Y, Zhang W, Hu X, Sun B, Cao G, Gao Y, et al: Omega-3 fatty acids protect the brain against ischemic injury by activating Nrf2 and upregulating heme oxygenase 1. J Neurosci 34: 1903-1915, 2014.

2. Zhao Y, Fu B, Zhang X, Zhao T, Chen L, Zhang J and Wang X: Paeonol pretreatment attenuates cerebral ischemic injury via upregulating expression of pAkt, Nrf2, HO-1 and ameliorating BBB permeability in mice. Brain Res Bull 109: 61-67, 2014.

3. Sanderson TH, Reynolds CA, Kumar R, Przyklenk K and Huttemann M: Molecular mechanisms of ischemia-reperfusion injury in brain: Pivotal role of the mitochondrial membrane potential in reactive oxygen species generation. Mol Neurobiol 47: 9-23, 2013.

4. Tuma RF and Steffens S: Targeting the endocannabinod system to limit myocardial and cerebral ischemic and reperfusion injury. Curr Pharm Biotechnol 13: 46-58, 2012.

5. Ishibashi N, Prokopenko O, Reuhl KR and Mirochnitchenko O: Inflammatory response and glutathione peroxidase in a model of stroke. J Immunol 168: 1926-1933, 2002.

6. Pan J, Konstas AA, Bateman B, Ortolano GA and Pile-Spellman J: Reperfusion injury following cerebral ischemia: Pathophysiology, MR imaging, and potential therapies. Neuroradiology 49: 93-102, 2007.

7. Cai F, Li CR, Wu JL, Chen JG, Liu C, Min Q, Yu W, Ouyang CH and Chen JH: Theaflavin ameliorates cerebral ischemia-reperfusion injury in rats through its anti-inflammatory effect and modulation of STAT-1. Mediators Inflamm 2006: 30490, 2006.

8. Amantea D, Nappi G, Bernardi G, Bagetta G and Corasaniti MT: Post-ischemia brain damage: Pathophysiology and role of inflammatory mediators. FEBS J 276: 13-26, 2009.

9. Beech JS, Reckless J, Mosedale DE, Grainger DJ, Williams SC and Menon DK: Neuroprotection in ischemia-reperfusion injury: An antiinflammatory approach using a novel broad-spectrum chemokine inhibitor. J Cereb Blood Flow Metab 21: 683-689, 2001.

10. Chen L, Wang L, Zhang X, Cui L, Xing Y, Dong L, Liu Z, Li Y, Zhang $\mathrm{X}$, Wang $\mathrm{C}$, et al: The protection by octreotide against experimental ischemic stroke: Up-regulated transcription factor Nrf2, HO-1 and down-regulated NF- $\kappa \mathrm{B}$ expression. Brain Res 1475: 80-87, 2012.

11. Frangogiannis NG: Chemokines in ischemia and reperfusion. Thromb Haemost 97: 738-747, 2007.

12. Wong $\mathrm{CH}$ and Crack PJ: Modulation of neuro-inflammation and vascular response by oxidative stress following cerebral ischemia-reperfusion injury. Curr Med Chem 15: 1-14, 2008.

13. Berti R, Williams AJ, Moffett JR, Hale SL, Velarde LC, Elliott PJ, Yao C, Dave JR and Tortella FC: Quantitative real-time RT-PCR analysis of inflammatory gene expression associated with ischemia-reperfusion brain injury. J Cereb Blood Flow Metab 22: 1068-1079, 2002

14. Hill-Kapturczak N, Jarmi T and Agarwal A: Growth factors and heme oxygenase-1: Perspectives in physiology and pathophysiology. Antioxid Redox Signal 9: 2197-2207, 2007.

15. Sharp FR, Zhan X and Liu DZ: Heat shock proteins in the brain: Role of Hsp70, Hsp 27 and HO-1 (Hsp32) and their therapeutic potential. Transl Stroke Res 4: 685-692, 2013. 
16. Liang C, Cang J, Wang H and Xue Z: Propofol attenuates cerebral ischemia/reperfusion injury partially using heme oxygenase-1. J Neurosurg Anesthesiol 25: 311-316, 2013.

17. Yang Y, Wang J, Li Y, Fan C, Jiang S, Zhao L, Di S, Xin Z, Wang B, Wu G, et al: HO-1 Signaling activation by pterostilbene treatment attenuates mitochondrial oxidative damage induced by cerebral ischemia reperfusion injury. Mol Neurobiol 53: 2339-2353, 2016.

18. Yang Y, Li X, Zhang L, Liu L, Jing G and Cai H: Ginsenoside $\mathrm{Rg} 1$ suppressed inflammation and neuron apoptosis by activating PPAR $\gamma / \mathrm{HO}-1$ in hippocampus in rat model of cerebral ischemia-reperfusion injury. Int J Clin Exp Pathol 8: 2484-2494, 2015.

19. Sarady-Andrews JK, Liu F, Gallo D, Nakao A, Overhaus M, Ollinger R, Choi AM and Otterbein LE: Biliverdin administration protects against endotoxin-induced acute lung injury in rats. Am J Physiol Lung Cell Mol Physiol 289: L1131-L1137, 2005.

20. Wegiel B, Baty CJ, Gallo D, Csizmadia E, Scott JR, Akhavan A Chin BY, Kaczmarek E, Alam J, Bach FH, et al: Cell surface biliverdin reductase mediates biliverdin-induced anti-inflammatory effects via phosphatidylinositol 3-kinase and Akt. J Biol Chem 284: 21369-21378, 2009.

21. Wegiel B, Gallo D, Csizmadia E, Roger T, Kaczmarek E, Harris C, Zuckerbraun BS and Otterbein LE: Biliverdin inhibits Toll-like receptor-4 (TLR4) expression through nitric oxide-dependent nuclear translocation of biliverdin reductase. Proc Natl Acad Sci USA 108: 18849-18854, 2011.

22. Bellner L, Wolstein J, Patil KA, Dunn MW and LaniadoSchwartzman M: Biliverdin rescues the HO-2 null mouse phenotype of unresolved chronic inflammation following corneal epithelial injury. Invest Ophthalmol Vis Sci 52: 3246-3253, 2011.

23. Nakagami T, Toyomura K, Kinoshita T and Morisawa S: A beneficial role of bile pigments as an endogenous tissue protector: Anti-complement effects of biliverdin and conjugated bilirubin. Biochim Biophys Acta 1158: 189-193, 1993.

24. Guha M and Mackman N: The phosphatidylinositol 3-kinase-Akt pathway limits lipopolysaccharide activation of signaling pathways and expression of inflammatory mediators in human monocytic cells. J Biol Chem 277: 32124-32132, 2002.

25. Longa EZ, Weinstein PR, Carlson S and Cummins R: Reversible middle cerebral artery occlusion without craniectomy in rats. Stroke 20: 84-91, 1989.

26. Meng YC, Ding ZY, Wang HQ, Ning LP and Wang C: Effect of microRNA-155 on angiogenesis after cerebral infarction of rats through AT1R/VEGFR2 pathway. Asian Pac J Trop Med 8 829-835, 2015

27. Chen J, Li Y, Wang L, Zhang Z, Lu D, Lu M and Chopp M: Therapeutic benefit of intravenous administration of bone marrow stromal cells after cerebral ischemia in rats. Stroke 32: 1005-1011, 2001

28. Hu Q, Chen C, Yan J, Yang X, Shi X, Zhao J, Lei J, Yang L, Wang K, Chen L, et al: Therapeutic application of gene silencing MMP-9 in a middle cerebral artery occlusion-induced focal ischemia rat model. Exp Neurol 216: 35-46, 2009.

29. Livak KJ and Schmittgen TD: Analysis of relative gene expression data using real-time quantitative PCR and the 2(-Delta Delta C(T)) Method. Methods 25: 402-408, 2001.

30. Welling LC, Welling MS, Teixeira MJ and Figueiredo EG: Fueling the brain-a new role in lactate metabolism. World Neurosurg 84: 611-612, 2015

31. Chen L, Xue Z and Jiang H: Effect of propofol on pathologic time-course and apoptosis after cerebral ischemia-reperfusion injury. Acta Anaesthesiol Scand 52: 413-419, 2008.

32. Yang GY and Betz AL: Reperfusion-induced injury to the blood-brain barrier after middle cerebral artery occlusion in rats. Stroke 25: 1658-1665, 1994.

33. Aronowski J, Strong R and Grotta JC: Reperfusion injury: Demonstration of brain damage produced by reperfusion after transient focal ischemia in rats. J Cereb Blood Flow Metab 17: 1048-1056, 1997.
34. Stanimirovic D and Satoh K: Inflammatory mediators of cerebral endothelium: A role in ischemic brain inflammation. Brain Pathol 10: 113-126, 2000.

35. Tang LM, Wang YP, Wang K, Pu LY, Zhang F, Li XC, Kong LB, Sun BC, Li GQ and Wang XH: Exogenous biliverdin ameliorates ischemia-reperfusion injury in small-for-size rat liver grafts. Transplant Proc 39: 1338-1344, 2007.

36. Beschorner R, Adjodah D, Schwab JM, Mittelbronn M, Pedal I, Mattern R, Schluesener HJ and Meyermann R: Long-term expression of heme oxygenase-1 (HO-1, HSP-32) following focal cerebral infarctions and traumatic brain injury in humans. Acta Neuropathol 100: 377-384, 2000.

37. Chao XD, Ma YH, Luo P, Cao L, Lau WB, Zhao BC, Han F, Liu W, Ning WD, Su N, et al: Up-regulation of heme oxygenase-1 attenuates brain damage after cerebral ischemia via simultaneous inhibition of superoxide production and preservation of NO bioavailability. Exp Neurol 239: 163-169, 2013.

38. Aztatzi-Santillán E, Nares-López FE, Márquez-Valadez B, Aguilera $\mathrm{P}$ and Chánez-Cárdenas ME: The protective role of heme oxygenase-1 in cerebral ischemia. Cent Nerv Syst Agents Med Chem 10: 310-316, 2010.

39. Lee JC, Kim IH, Park JH, Ahn JH, Cho JH, Cho GS, Tae HJ, Chen BH, Yan BC, Yoo KY, et al: Ischemic preconditioning protects hippocampal pyramidal neurons from transient ischemic injury via the attenuation of oxidative damage through upregulating heme oxygenase-1. Free Radic Biol Med 79: 78-90, 2015.

40. Fondevila C, Shen XD, Tsuchiyashi S, Yamashita K, Csizmadia E, Lassman C, Busuttil RW, Kupiec-Weglinski JW and Bach FH: Biliverdin therapy protects rat livers from ischemia and reperfusion injury. Hepatology 40: 1333-1341, 2004.

41. Wang J, Zhou HC, Pan P, Zhang N and Li WZ: Exogenous biliverdin improves the function of lung grafts from brain dead donors in rats. Transplant Proc 42: 1602-1609, 2010.

42. Kosaka J, Morimatsu H, Takahashi T, Shimizu H, Kawanishi S, Omori E, Endo Y, Tamaki N, Morita M and Morita K: Effects of biliverdin administration on acute lung injury induced by hemorrhagic shock and resuscitation in rats. PLoS One 8: e63606, 2013

43. Overhaus M, Moore BA, Barbato JE, Behrendt FF, Doering JG and Bauer AJ: Biliverdin protects against polymicrobial sepsis by modulating inflammatory mediators. Am J Physiol Gastrointest Liver Physiol 290: G695-G703, 2006.

44. Nakao A, Otterbein LE, Overhaus M, Sarady JK, Tsung A, Kimizuka K, Nalesnik MA, Kaizu T, Uchiyama T, Liu F, et al: Biliverdin protects the functional integrity of a transplanted syngeneic small bowel. Gastroenterology 127: 595-606, 2004.

45. Nakao A, Neto JS, Kanno S, Stolz DB, Kimizuka K, Liu F, Bach FH, Billiar TR, Choi AM, Otterbein LE and Murase N: Protection against ischemia/reperfusion injury in cardiac and renal transplantation with carbon monoxide, biliverdin and both. Am J Transplant 5: 282-291, 2005.

46. Fondevila C, Katori M, Lassman C, Carmody I, Busuttil RW, Bach FH and Kupiec-Weglinski JW: Biliverdin protects rat livers from ischemia/reperfusion injury. Transplant Proc 35: 1798-1799, 2003.

47. Stoll G, Kleinschnitz C and Nieswandt B: Combating innate inflammation: A new paradigm for acute treatment of stroke? Ann N Y Acad Sci 1207: 149-154, 2010.

48. Maddahi A and Edvinsson L: Cerebral ischemia induces microvascular pro-inflammatory cytokine expression via the MEK/ERK pathway. J Neuroinflammation 7: 14, 2010.

49. Denes A, Thornton P, Rothwell NJ and Allan SM: Inflammation and brain injury: Acute cerebral ischaemia, peripheral and central inflammation. Brain Behav Immun 24: 708-723, 2010

50. Yaidikar L and Thakur S: Punicalagin attenuated cerebral ischemia-reperfusion insult via inhibition of proinflammatory cytokines, up-regulation of $\mathrm{Bcl}-2$, down-regulation of Bax, and caspase-3. Mol Cell Biochem 402: 141-148, 2015. 